\title{
Dialogando con Mario Rovere sobre el artículo “Atención Primaria de Salud en Debate"
}

Dialoging with Mario Rovere about the article "Debate on Primary Health Care"

Oscar Feo ${ }^{1}$

Especialista en Salud Pública y Salud de los Trabajadores; Profesor Titular de la Universidad de Carabobo, Venezuela; Consultor del Instituto Suramericano de Gobierno en Salud (ISAGS) de Unión de Naciones Suramericanas (UNASUR) - Venezuela.

oscarfeo@msn.com
La redacción de la revista Saúde em Debate me ha invitado a comentar el artículo del buen amigo Mario Rovere, titulado "Atención Primaria en Salud en Debate", lo cual hago con mucho gusto, en primer lugar señalando que sus muchas preguntas tienen el efecto mágico de abrir nuevas perspectivas, nos invitan a explorar otras dimensiones de la atención primaria de salud (APS) y a reflexionar de forma más concienzuda sobre un tema, que, como él dijo, ha marcado los caminos de la Salud Pública en los últimos años. Sin embargo, en este breve comentario solamente voy a reforzar algunas ideas presentes en el artículo de Rovere:

- hay numerosas experiencias de APS previas a la 'Alma Ata', muchas de ellas con gran sentido comunitario, de participación y educación popular;

- no se logró una adecuada comprensión de lo que significaba la APS, ni hubo suficiente voluntad política para impulsar los cambios que requería su desarrollo;

- una visión 'reduccionista' prevalente en diversos organismos internacionales convirtió la APS original en una selectiva, quitándole su significado integrador y de justicia social.

\section{Atención primaria de salud y alma ata}

Mucha gente cree que la APS tuvo su origen en 'Alma Ata', pero es necesario recordar que existieron muchas experiencias previas, dos de ellas muy notables y conocidas: la rusa, con los muy antiguos Feldsher, y la china, con los más recientes médicos descalzos que acompañaron la revolución cultural a finales de la década de los 1960, ambas basadas en personal no médico, entrenado para resolver problemas de salud a nivel rural. Pero mencionaré también dos experiencias más cercanas y menos conocidas: la primera, la 'medicina simplificada' en Venezuela, donde a partir de 1962 el Ministerio de Salud desarrolló una propuesta para llevar salud a regiones rurales muy apartadas, entrenando a pobladores de esas comunidades, para convertirlos en 'auxiliares de medicina simplificada'. Fue una experiencia de gran valor, llegaron a existir cerca de 3.000 ambulatorios rurales atendidos por estos auxiliares, convirtiéndose en un modelo que generó interés en muchos países y organismos interna- 
cionales. La segunda experiencia, centroamericana, fue resaltada por Hamlin, en su texto, "Donde comienza la vida comienza la Atención Primaria en Salud”, con programas de salud comunitaria, desarrollados con fuerte influencia de la iglesia progresista, la teología de la liberación y las ideas de Paulo Freire sobre educación popular. Todas ellas con fuerte participación popular (ZUNIGA, 2003).

Sin embargo, fue a partir de la Conferencia Internacional sobre APS, convocada por la Organización Mundial de la Salud (OMS) y realizada en Alma Ata en 1978, que la APS se difundió e institucionalizó mundialmente. Eso ha ocurrido, en parte, gracias a un singular documento, conocido como "Declaración de Alma Ata”, de mucha importancia en la historia de la salud mundial, y que tiene el gran valor de reconocer las graves desigualdades existentes y que reclama un 'nuevo orden mundial' que permitiera 'salud para todos' a través de la estrategia de APS, incorporando conceptos claves que enumeramos a continuación, y que luego serían desestimados por las visiones hegemónicas del pensamiento médico:

- la salud como derecho fundamental del ser humano, seńalando la responsabilidad del Estado para garantizarla;

- la universalidad y la integralidad como elementos claves de la organización del cuidado a la salud, reconociendo y exigiendo acción intersectorial;

- la organización y participación de la comunidad como componente central de la construcción social de la salud;

- además, plantea el tema de la necesidad de recursos humanos apropiados para su desarrollo.

No obstante, esta declaración contiene una debilidad muy importante, al considerar a la APS como 'atención sanitaria esencial' basada en métodos y tecnologías prácticos, lo cual condujo a algunos organismos internacionales a reducir la APS a 'acción selectiva', convirtiéndola en 'atención primitiva’ para los más pobres. Eso ha sido señalado como el 'pecado original' de la "Alma Ata". En ese camino se perdió la carga política transformadora de la idea de Salud para Todos y de la necesidad de un nuevo orden mundial, y se dio mayor relevancia al término APS como estrategia desprovista de su sentido inicial. Como señala Rovere, la APS ha servido para todo, para programas realmente transformadores, o para que los organismos financieros promuevan paquetes de servicios.

\section{¿Por qué no se logró una adecuada com- prensión de su significado?}

Es evidente que el término APS generó mucha confusión, aun hay países donde APS remite exclusivamente al primer nivel de atención, mientras que en otros a programas especiales para las poblaciones más pobres, dejando a un lado las ideas centrales de la APS.

Sobre el término APS, es interesante la lectura del texto 'Alma Ata: 25 años después' de David Tejada, quien como parte de los organizadores de 'Alma Ata' narra los detalles de esa reunión, por ejemplo el papel protagónico de la URSS y su relación con el conflicto chino soviética, pero, sobre todo, critica la traducción del término 'Primary Health Care' por Atención Primaria en Salud, señalando que fue el inicio de una serie de pasos que conducirían al fracaso y a la inoperancia de esa estrategia. Según Rivero (2004), el término que debió ser usado era 'Cuidado Integral de la Salud', lo cual reflejaba mejor la condición de estrategia, mientras que el término 'atención' reducía la APS a simple atención a la enfermedad, muchas veces concebida como 'atención primaria selectiva' sólo para algunos problemas, o 'primitiva’ para los pobres.

\section{¿Por qué 35 años después de 'alma ata' no ha sido posible conseguir salud para todos, ni consolidar la atención primaria en salud como estrategia para la organización de los sistemas de salud?}

Mahler (1981), gran sanitarista danés, para ese entonces director de la OMS, clausuró la conferencia de 
'Alma Ata' con un discurso memorable, en el cual formulaba cinco preguntas, que definirían el éxito y futuro de la APS, algunas de ellas eran:

- ¿hay disposición para enfrentar el abismo que separa los 'privilegiados' de los 'desposeídos'?;

- ¿estamos dispuestos a cambiar los servicios de salud, colocando a la APS en el centro?:

- ¿estamos dispuestos a comprometernos políticamente y asignar los recursos necesarios?;

- ¿estamos dispuestos a movilizar a la gente?;

- ¿estamos dispuestos a superar las resistencias sociales, económicas y profesionales?

En esas preguntas está la clave del porqué la APS no tuvo éxito, es evidente que no hubo ni el compromiso político para superar las desigualdades, ni para construir un nuevo orden mundial, indispensables para que hubiese habido Salud para Todos en 2000. Treinta y cinco años después se han realizado muchas reuniones y comisiones para analizar las causas que impidieron ese logro. En algunas de ellas se ha planteado su relanzamiento, desarrollando una propuesta de 'Sistemas de Salud basados en APS'.

Consideramos importante rescatar las conclusiones de algunas de esas comisiones, tratando de aprender las lecciones y evitar que en 30 años más tengamos que volver a analizar por qué no hay salud para todos.

Es indispensable el compromiso político de los gobiernos para hacer de la Salud para Todos una prioridad y garantizarle los recursos necesarios.
Es necesario comprender la determinación social de la salud y la enfermedad, dejar de lado la visión centrada en el sector salud y desarrollar acción intersectorial comprendida como políticas públicas de carácter integral para elevar la calidad de la vida, y mejorar colectivamente la salud.

Es indispensable cambiar el modelo de formación de profesionales y técnicos de la salud, hoy dirigidos a la sub especialización y marcados por las formas cada vez más deshumanizadas y mercantilizadas de las prácticas de la salud, pasando a un modelo de formación más integral, solidario y humano, que permita desarrollar sistemas universales de salud y nuevos modelos de atención.

Hay también la necesidad de participación real de las comunidades y organizaciones sociales. Un elemento en el fracaso de la APS fue la ausencia o instrumentalización de la participación, cooptada por el pensamiento hegemónico, que hace que todos hablan de participación, pero no la haya en realidad. La participación es un problema de poder y de capacidad real para decidir. Participación, redistribución del poder y capacidad de decisión son factores claves para una verdadera participación transformadora.

En conclusión, las preguntas de Mahler hace 35 ańos tienen plena vigencia; si queremos recuperar el ideal de Salud para Todos, debemos comprometernos políticamente, fortalecer y reorientar los sistemas públicos de salud hacia la universalidad y la integralidad, y confrontar el pensamiento médico hegemónico, centrado en la enfermedad, para pasar a uno que permita comprender y actuar sobre los determinantes reales de la salud.

\section{Referências}

MACINKO, J. et al. La renovación de la atención primaria de salud en las Américas. Revista Panamericana de Salud Pública, Washington, v. 21, mar. 2007, p. 73-84.

MAHLER, H. The meaning of Health for All by the year 2000. World Health Forum, Genebra, v. 2, n. 1, p. 05-22, 1981.
RIVERO, D. T. Alma Ata: 25 años después. Perspectivas de Salud, Washington, v. 13, n. 2, 2004, p.51-54.

ZÚNIGA, M. Z. Donde comienza la vida comienza la Atención Primaria en Salud. Managua: Comité Regional de Promoción de Salud Comunitaria, 2003. 32p. 